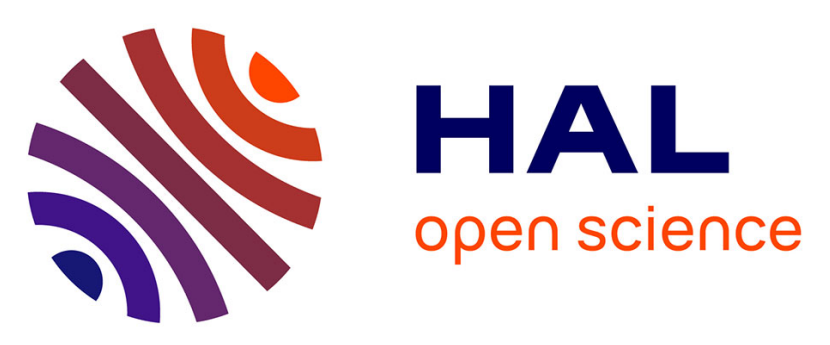

\title{
A randomized phase III study of adjuvant platinum/docetaxel chemotherapy with or without radiation therapy in patients with gastric cancer
}

Aristotelis Bamias, M. Karina, P. Papakostas, I. Kostopoulos, M. Bobos, G. Vourli, E. Samantas, Ch. Christodoulou, G. Pentheroudakis, D. Pectasides, et al.

\section{To cite this version:}

Aristotelis Bamias, M. Karina, P. Papakostas, I. Kostopoulos, M. Bobos, et al.. A randomized phase III study of adjuvant platinum/docetaxel chemotherapy with or without radiation therapy in patients with gastric cancer. Cancer Chemotherapy and Pharmacology, 2010, 65 (6), pp.1009-1021. 10.1007/s00280-010-1256-6 . hal-00562713

\section{HAL Id: hal-00562713 https://hal.science/hal-00562713}

Submitted on 4 Feb 2011

HAL is a multi-disciplinary open access archive for the deposit and dissemination of scientific research documents, whether they are published or not. The documents may come from teaching and research institutions in France or abroad, or from public or private research centers.
L'archive ouverte pluridisciplinaire HAL, est destinée au dépôt et à la diffusion de documents scientifiques de niveau recherche, publiés ou non, émanant des établissements d'enseignement et de recherche français ou étrangers, des laboratoires publics ou privés. 


\title{
A randomized phase III study of adjuvant platinum/docetaxel chemotherapy with or without radiation therapy in patients with gastric cancer
}

\author{
Aristotelis Bamias • M. Karina - P. Papakostas • I. Kostopoulos • M. Bobos • \\ G. Vourli • E. Samantas • Ch. Christodoulou • G. Pentheroudakis • \\ D. Pectasides • M. A. Dimopoulos • G. Fountzilas
}

Received: 15 October 2009 / Accepted: 12 January 2010 / Published online: 4 February 2010

(C) Springer-Verlag 2010

\begin{abstract}
The optimal adjuvant treatment for gastric cancer remains controversial. We compared the efficacy of a docetaxel and platinum adjuvant chemotherapy regimen, in patients with high-risk gastric cancer, with that of the same chemotherapy plus radiation therapy (RT). In addition, we evaluated the prognostic and/or predictive value of a panel of molecular markers. Patients with histologically proven, radically resected gastric cancer, stage $\geq \mathrm{T} 3$ and/or $\mathrm{N}+$ were randomized to 6 cycles of docetaxel with cisplatin, both at $75 \mathrm{mg} / \mathrm{m}^{2}$ every 3 weeks (arm A) or the same treatment with RT (arm B; 45 Gy). Due to excessive nausea and vomiting, cisplatin was substituted by carboplatin at AUC (area under the curve) of 5 after the first 45 patients (22 group A, 23 group B). The prognostic value of EGFR, ERCC1, HER2, MET/HGFR, MAP-Tau, and PTEN expression was also studied in a subset of 67 patients using
\end{abstract}

\footnotetext{
A. Bamias · M. A. Dimopoulos

Department of Clinical Therapeutics,

University of Athens School of Medicine, Athens, Greece

M. Karina $\cdot$ G. Fountzilas

Department of Medical Oncology, "Papageorgiou" Hospital,

Aristotle University of Thessaloniki School of Medicine,

Thessaloniki, Greece

P. Papakostas

Department of Medical Oncology,

"Hippokration" Hospital, Athens, Greece

I. Kostopoulos $\cdot$ M. Bobos

Department of Pathology,

Aristotle University of Thessaloniki School of Medicine,

Thessaloniki, Greece

G. Vourli

Hellenic Cooperative Oncology Group Data Office,

Section of Biostatistics, Athens, Greece
}

immunohistochemistry on tissue microarrays (TMAs). A total of 147 patients were randomized. After a median follow-up of 53.7 months, no differences in overall (OS) and diseasefree survival (DFS) were found between the two arms. The most common grade 3/4 toxicities for arms $\mathrm{A}$ and $\mathrm{B}$ (excluding alopecia) were non-febrile neutropenia (11 and $17 \%$, respectively), febrile neutropenia (9 and 7\%) and diarrhea (7 and 4\%, respectively). Patients with ERCC1 positive tumors had significantly longer median DFS (33.1 vs. 11.8 months, Wald $P=0.016)$ and OS (63.2 vs. 18.8 months, Wald $P=0.046$ ). Our results indicate that the addition of RT to platinum/docetaxel adjuvant chemotherapy does not appear to improve survival in high-risk, radically resected gastric cancer. However, the possibility that a benefit by the addition of RT was not detected due to decreased power of the study should not be excluded.

\author{
E. Samantas \\ Third Department of Medical Oncology, \\ “Agii Anargiri” Cancer Hospital, Athens, Greece \\ Ch. Christodoulou \\ Second Department of Medical Oncology, \\ "Metropolitan" Hospital, Piraeus, Greece \\ G. Pentheroudakis \\ Department of Medical Oncology, \\ Ioannina University Hospital, Ioannina, Greece \\ D. Pectasides \\ Second Department of Internal Medicine, \\ Propaedeutic, Oncology Section, \\ "Attikon" University Hospital, Athens, Greece
}

\author{
A. Bamias $(\square)$ \\ Oncology Unit, Alexandra Hospital, \\ 80 Vas. Sofias Ave., 115 28, Athens, Greece \\ e-mail: abamias@med.uoa.gr
}


Keywords Adjuvant chemotherapy - Gastric cancer . Docetaxel · Radiotherapy · TMA · ERCC1 - HER2 . MAP-Tau

\section{Introduction}

Gastric cancer is the fourth most common cancer and the second highest cause of cancer deaths worldwide [1]. Each year in Europe, an estimated 192,000 new cases of gastric cancer are diagnosed, with the disease accounting for about 158,000 deaths in 2000 [2]. The treatment of choice for patients diagnosed with gastric cancer is surgical resection of the primary tumor and regional lymph nodes [3]. However, even in patients presenting with early stage disease, about $60 \%$ eventually have local relapse or distant metastases after curative resection [4]. Various adjunctive therapies (such as chemotherapy, radiation therapy [RT], or immunotherapy) have been studied in an attempt to improve survival in patients with resectable gastric cancer [5-7]. The role of adjuvant therapies has only recently been clarified, following the results of three well designed randomized studies with more than 500 patients included in each, all showing a survival benefit [8-10]. Nevertheless, different strategies were used: chemoradiotherapy [8], neoadjuvant plus adjuvant chemotherapy [9], and adjuvant chemotherapy [10]. Therefore, it is still unclear what the optimal adjuvant therapy is for resected gastric cancer.

Chemoradiotherapy has recently been associated with a significant survival benefit in gastric cancer [8]. The chemotherapy regimen consisted of 5-fluorouracil and leucovorin, a combination with minimal efficacy in advanced disease. In addition, the quality of surgery in that study was questionable, with the majority of patients undergoing a D0 resection. These two points would therefore question the efficacy of RT, if more effective chemotherapy and/or more appropriate surgery had been applied. The dilemma becomes even more relevant when the toxicity associated with RT and the difficulties of monitoring the quality of RT are considered.

Several novel chemotherapeutic agents appear to have promising efficacy in advanced disease. Docetaxel has shown considerable efficacy as single-agent [11] and as part of a combination therapy [4, 12]. In particular, docetaxel and cisplatin have been reported to show at least additive efficacy when used as combination therapy [13], and their demonstrated efficacy and tolerability make this regimen particularly applicable to the adjuvant setting [14].

Another approach to improve the efficacy of adjuvant strategies is the detection of factors, which might aid the selection of patients with a better prognosis or an improved response to treatment. Biological markers (such as estrogen receptors, HER2 status, and KRAS mutations) are currently used in other neoplasms to select patients for specific therapies [15-17]. Biological prognostic factors can be derived from genetic processes that represent crucial steps to carcinogenesis. Others can be predictive of response to therapy, as they are targets of chemotherapy or targeted therapies. Such markers are under study in gastric cancer but results are non-conclusive yet [18].

Based on the above data, this study aimed to compare the efficacy of chemoradiotherapy, consisting of RT plus a modern chemotherapy regimen, with the same regimen without RT, as adjuvant treatment in patients in high-risk for relapse after curative resection of gastric cancer. In addition, we studied the prognostic and/or predictive value of molecular markers, namely epidermal growth factor receptor (EGFR), excision repair cross-complementing group-1 (ERCC1), HER2, Met proto-oncogene tyrosine kinase/hepatocyte growth factor receptor (MET/HGFR), MAP-Tau (microtubule-associated protein Tau), and PTEN/MMAC1 (phosphatase and tensin homolog, mutated in multiple advanced cancers 1).

\section{Patients and methods}

\section{Patients}

Patients with histologically confirmed gastric adenocarcinoma (including adenocarcinoma of the gastroesophageal junction) were included in the study. Only surgeons performing a minimum of 20 operations for gastric cancer per year were accepted to participate. Patients were eligible for post-operative adjuvant therapy if: disease was absent from the peritoneal cavity and other distant organs, negative surgical margins were obtained, had serosal infiltration (pT3 based on American Joint Committee on Cancer criteria [19]) or infiltrated lymph nodes; they had performance status 2 or lower according to the Eastern Cooperative Oncology Group criteria; they had no history of other malignancy except basal cell or squamous cell carcinoma of the skin; were at least 18 years of age; had no evidence of cardiac failure; had absolute neutrophil count $>1,500 \mu \mathrm{L}^{-1}$, platelet count $>100,000 \mathrm{~mL}^{-1}$, normal serum bilirubin, alanine transaminase and aspartate transaminase $<2$ times the upper limit of normal, and calculated creatinine clearance $>60 \mathrm{~mL} \mathrm{~min}^{-1}$; and were of satisfactory nutritional status (weight increase following gastrectomy or minimum intake of $1,500 \mathrm{kcal} \mathrm{day}^{-1}$ ). The clinical protocol and collateral translational research studies were approved by the HeCOG Protocol Review Committee and by the Bioethics Committee of the Aristotle University of Thessaloniki School of Medicine. The study was registered at the Australian New Zealand Clinical Trials Registry (No. 308272). All patients gave their informed consent prior to study entry. 


\section{Treatment}

Patients were randomized to one of the following regimens: (1) Six cycles of docetaxel with cisplatin (group A) and (2) Six cycles of docetaxel with cisplatin and RT (group B). After the first 45 patients (22 group A, 23 group B), the protocol was amended due to excessive nausea and vomiting and cisplatin was substituted by carboplatin.

The doses of the chemotherapeutic agents used were $75 \mathrm{mg} \mathrm{m}^{-2}$ docetaxel in $250 \mathrm{~mL}$ saline administered over a 1-h period; $75 \mathrm{mg} \mathrm{m}^{-2}$ cisplatin in $500 \mathrm{~mL}$ saline administered over a 1-h period or carboplatin to an area under the curve (AUC) of 5 in $500 \mathrm{~mL}$ saline or $5 \%$ dextrose administered over a 1-h period; treatment was administered every 3 weeks for six cycles. A minimum of $3 \mathrm{~L}$ of hydration was given with cisplatin administration. Before receiving the chemotherapy regimen, patients were given $5-\mathrm{HT}_{3}$ antagonists with $20 \mathrm{mg}$ dexamethasone, $4 \mathrm{mg}$ dimentindine maleate, and $50 \mathrm{mg}$ ranitidine. On the day before and the 3 days after treatment, patients received $4 \mathrm{mg}$ methyl prednisolone twice daily. Treatment was administered if $\mathrm{ANC} \geq 1,500$ and PLT $\geq 100,000$, otherwise it was delayed for a week. Drug doses were reduced by $20 \%$ in case of grade 3 or 4 neutropenia or thrombocytopenia. G-CSF was used in case of repeated delays or neutropenic fever. Cisplatin was discontinued in case of nephrotoxicity, grade $>2$. In case of stomatitis or diarrhea grade $\geq 2$ treatment was delayed until toxicity was reduced to grade 1 . Docetaxel was reduced by $20 \%$ in case of grade $>2$ or repeated grade 2 hematological toxicity.

Radiation therapy (RT) was administered 3-4 weeks after the third chemotherapy cycle. RT was planned with dedicated computed tomography (CT) and a threedimensional planning system. It was delivered with linear accelerators with nominal energy of 6 and/or $18 \mathrm{MV}$, through parallel-opposed AP-PA fields. RT consisted of fractionated external irradiation at a dose of $1.8 \mathrm{~Gy}$ per fraction given once daily 5 days per week (Monday through Friday) over a period of 5 weeks, for a total dose of $45 \mathrm{~Gy}$. Target volume included the tumor bed, identified on the preoperative $\mathrm{CT}$, the anastomoses, the stomach remnant, as well as the regional lymphatics. In cases of proximal T3 lesions, the medial left hemidiaphragm was also included in the radiation fields. The regional lymph nodes irradiated were the perigastric, celiac, local paraortic, pancreaticoduodenal, portal hepatic, and splenic nodes. In patients with lesions of the antrum, the splenic nodes could be excluded. In patients with proximal lesions exclusion of the pancreaticoduodenal nodes was allowed. Doses were limited, so that less than $60 \%$ of the liver received more than $30 \mathrm{~Gy}$ and less than $30 \%$ of the cardiac volume received more than $40 \mathrm{~Gy}$. An equivalent of at least three-fourths of one kidney was spared from doses higher than $20 \mathrm{~Gy}$. The treatment protocol did not include a central quality-assurance review of the radiotherapy plan.

RT was delayed in case of grade 3 diarrhea or myelotoxicity and was resumed upon reduction to grade 1 . Three further cycles of chemotherapy were administered 4-5 weeks after completion of RT. Prior to treatment, initiation, patients were assessed by abdominal computed tomography (CT), chest X-ray, complete blood count, biochemical examination, carcinoembryonic antigen, and carbohydrate antigen 19.9. These assessments were repeated 1 month after completion of therapy, every 6 months during the first 5 years of the study, and yearly thereafter. Upper GI endoscopy was performed on an annual basis.

\section{Tissue samples}

Formalin-fixed, paraffin-embedded tissue blocks from 69 gastrectomy specimens were collected. H\&E sections were reviewed by a pathologist (MB), and the most representative tumor areas were marked for the construction of the tissue microarrays (TMAs). Nine specimens with tumor accounting for $<5 \%$ of whole tissue area were not used for TMA construction, but whole tissue sections were used for immunohistochemistry.

\section{TMA construction}

Specimens were arrayed ( 5 cores per case, $0.6 \mathrm{~mm}$ in diameter) into two recipient paraffin blocks (Paraplast ${ }^{\circledR}$, McCormick, St. Louis, MO, USA) using a manual arrayer (Beecher Instruments, Sun Prairie, WI, USA). After construction, array blocks were placed in an incubator $\left(60^{\circ} \mathrm{C}\right)$ for $15 \mathrm{~min}$ in order to assist filling in the cracks and defects at the core-wax interface that could cause the loss of cores on the slides.

\section{Immunohistochemistry}

Immunohistochemical labeling was performed according to standard protocols with slight modifications [20], on serial 2.5- $\mu \mathrm{m}$ thick sections from the original blocks or the two TMA blocks. All slides of the study were stained in one run for each antibody. All cases were stained also for vimentin (clone V9, Dako), Ki-67 (clone MIB1, Dako), and cytokeratin 8/18 (CAM5.2, clone 5D3, Novocastra), which were used as control stains for tissue immunoreactivity and fixation, as well as for identification of tumor cells (CAM5.2). Samples negative for the above antibodies were excluded from the study. The evaluation of all IHC sections was done simultaneously by two observers, (I. K. and M. B.), blinded as to the patients' clinical characteristics and survival data, according to previously described criteria [21-25], with slight modifications for MET, ERCC1, and 
MAP-Tau. Briefly, for MET (clone 8F1, Novocastra), ERCC1 (clone 8F11, Thermo Fisher Scientific), and MAP-Tau (clone T1029, US Biological), a 4-tier range system was applied for intensity and staining pattern. Intensity was scored as follows: $0=$ no staining, $1=$ weakly positive, $2=$ moderately positive, and $3=$ strongly positive. The scoring of the staining pattern was based on the percentage of positive tumor cells: $0=0-5 \%, 1=6-25 \%, 2=26-50 \%$, $3=51-100 \%$ ). The localization of staining for each protein was also indicated, as cytoplasmic and cytoplasmic/membraneous for MET and nuclear, cytoplasmic and nuclear/ cytoplasmic for ERCC1 and MAP-Tau. In order to define the expression status of the above proteins, the total score was calculated as the sum of the intensity score and the staining pattern score. Cases with a total score of at least 2 were considered as positive (high-expressing tumors), whereas cases with a total score of $0-1$ were considered as negative or low-expressing tumors. EGFR (clone 31G7, Zymed) intensity of reactivity was scored using a four-tier system [24]: 0 (negative), no staining or background staining; 1+weak discontinuous membranous staining; $2+$ moderate complete or incomplete membranous staining; $3+$ strong and complete membranous staining. Cases were considered positive when more than $1 \%$ of tumor cells showed at minimum 1+ staining. HER2 (Dako) protein expression was scored $0-3+$ according to the modified breast IHC Hercep Test protocol (Dako). PTEN (clone $6 \mathrm{H} 2.1$, Dako) protein expression (cytoplasmic, nuclear or both) was evaluated according to a previously established rank scale of 0-2 [25]. Vascular endothelial cells and/or fibroblasts were used as control markers of staining intensity. Tumors with PTEN scores of 0 or 1 were considered to have PTEN loss.

\section{Randomization and statistical analysis}

Patients were centrally randomized and stratified according to study center, the depth of tumor infiltration and number of infiltrated nodes. The study was originally designed to identify a $20 \%$ increase in survival rate in the RT arm, assuming that the 5-year survival rate in arm A is $35 \%$. Therefore, 200 patients were needed, in order to have a trial with $80 \%$ statistical power at $a=0.05$ level of significance. Taking into account a 3\% withdrawal rate, 206 patients were needed for this trial. A 70 patients/year accrual rate was anticipated when the study was designed. This estimation was accurate for the first year; however, accrual declined during the second and third year. After 3 years, only 147 patients were randomized due to the decrease of the accrual rate over time. Thus, the Scientific Committee of HeCOG decided to suspend the study.

Analyses were conducted on an intent-to-treat basis. Overall survival (OS) was measured from the date of randomization until death from any cause and surviving patients were censored at the date of last contact. Diseasefree survival (DFS) was measured from randomization until relapse. Death without verified disease progression was considered as an event in the DFS analysis. Time to event distributions were estimated using Kaplan-Meier curves and compared using the log-rank test.

Fig. 1 Flow of the study

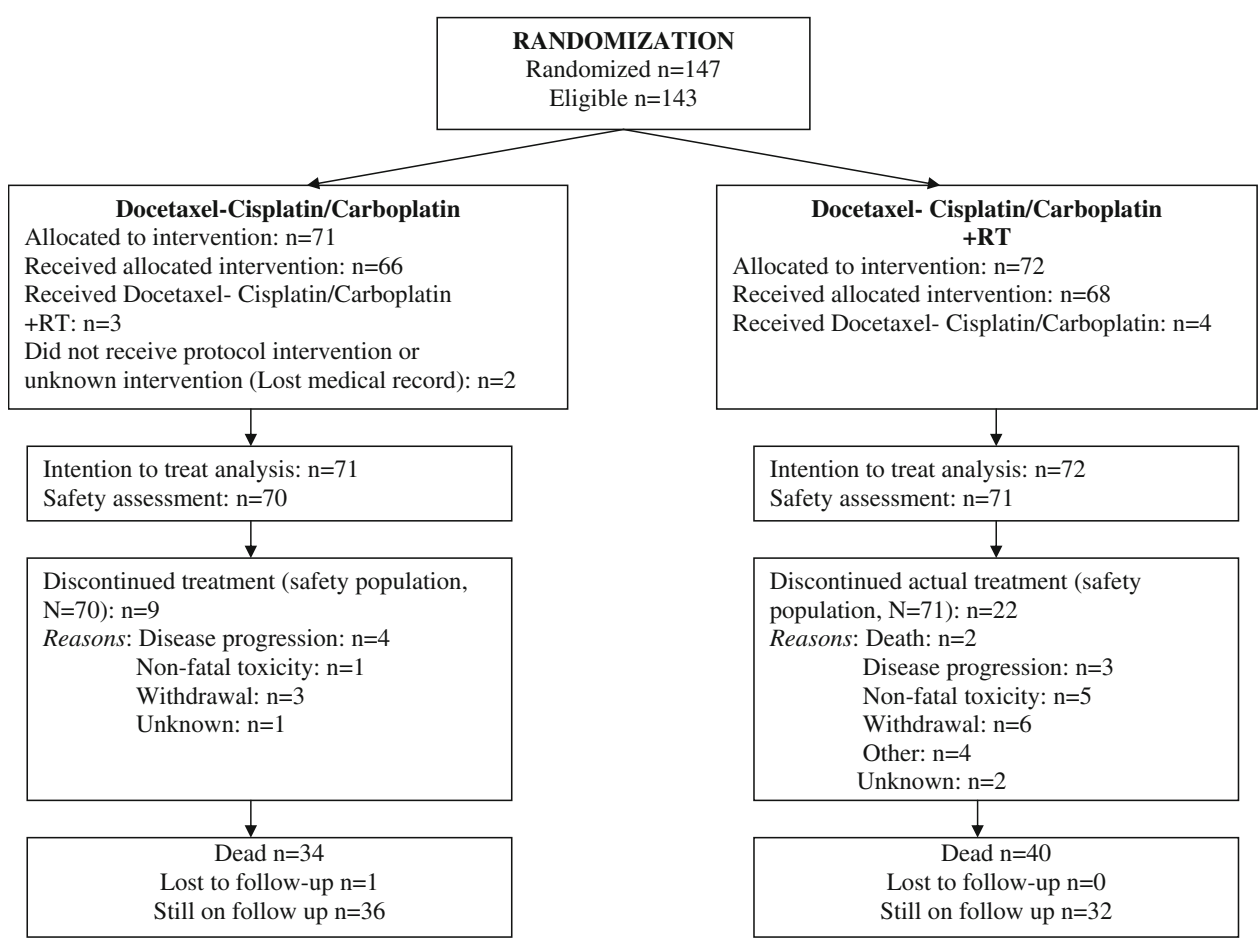


Table 1 Selective patient and tumor characteristics

\begin{tabular}{|c|c|c|c|c|c|}
\hline \multirow[t]{2}{*}{ Age, years [median (range)] } & & \multicolumn{2}{|c|}{$\frac{\operatorname{Arm} \mathrm{A}(N=71)}{62(41-79)}$} & \multicolumn{2}{|c|}{$\frac{\operatorname{Arm~B}(N=72)}{63(32-75)}$} \\
\hline & & $N$ & $(\%)$ & $N$ & $(\%)$ \\
\hline \multirow[t]{2}{*}{ Sex } & Female & 19 & 27 & 24 & 33 \\
\hline & Male & 52 & 73 & 48 & 67 \\
\hline \multirow[t]{3}{*}{ PS } & 0 & 58 & 82 & 56 & 78 \\
\hline & 1 & 12 & 17 & 15 & 21 \\
\hline & 2 & 1 & 1 & 1 & 1 \\
\hline \multirow[t]{4}{*}{$\mathrm{T}$} & 1 & 3 & 4 & 1 & 1 \\
\hline & 2 & 11 & 15 & 15 & 21 \\
\hline & 3 & 54 & 76 & 53 & 74 \\
\hline & 4 & 3 & 4 & 3 & 4 \\
\hline \multirow[t]{5}{*}{$N$} & 0 & 9 & 13 & 8 & 11 \\
\hline & 1 & 34 & 48 & 40 & 56 \\
\hline & 2 & 20 & 28 & 20 & 28 \\
\hline & 3 & 7 & 10 & 4 & 6 \\
\hline & Unknown & 1 & 1 & 0 & 0 \\
\hline \multirow[t]{6}{*}{ Tumor stage } & IB & 3 & 4 & 0 & 0 \\
\hline & II & 19 & 27 & 18 & 25 \\
\hline & IIIA & 23 & 32 & 34 & 47 \\
\hline & IIIB & 15 & 21 & 13 & 18 \\
\hline & IV & 10 & 14 & 7 & 10 \\
\hline & Unknown & 1 & 1 & 0 & 0 \\
\hline \multirow[t]{5}{*}{ Tumor grade } & Well & 4 & 6 & 3 & 4 \\
\hline & Moderate & 17 & 24 & 23 & 32 \\
\hline & Poor & 44 & 62 & 41 & 57 \\
\hline & Undifferentiated & 1 & 1 & 1 & 1 \\
\hline & Unknown & 5 & 7 & 4 & 6 \\
\hline \multirow[t]{3}{*}{ Histological subtype } & Intestinal & 26 & 37 & 43 & 60 \\
\hline & Diffuse & 42 & 59 & 23 & 32 \\
\hline & Mixed/Unclassified & 3 & 4 & 6 & 8 \\
\hline \multirow[t]{4}{*}{ Tumor location } & Proximal & 14 & 20 & 19 & 26 \\
\hline & Distal & 16 & 22 & 22 & 31 \\
\hline & Lesser curvature & 32 & 45 & 19 & 26 \\
\hline & Greater curvature & 9 & 13 & 12 & 17 \\
\hline \multirow[t]{5}{*}{ Type of Surgery } & Total gastrectomy \pm other & 29 & 41 & 28 & 39 \\
\hline & Subtotal gastrectomy \pm other & 35 & 49 & 38 & 53 \\
\hline & Esophagogastrectomy & 4 & 6 & 6 & 8 \\
\hline & Other & 1 & 1 & 0 & 0 \\
\hline & Unknown & 2 & 3 & 0 & 0 \\
\hline \multirow[t]{2}{*}{ Lymphadenectomy } & D0 & 38 & 54 & 42 & 58 \\
\hline & $\mathrm{D} 1+\mathrm{D} 2$ & 33 & 46 & 30 & 42 \\
\hline Lymph nodes examined [median (range)] & $14(0-62)$ & $14(3-76)$ & & & \\
\hline Lymph nodes involved [median (range)] & $4(0-47)$ & $4(0-56)$ & & & \\
\hline 0 & 11 & 16 & 8 & 11 & \\
\hline $1-3$ & 24 & 34 & 25 & 35 & \\
\hline $4-10$ & 22 & 31 & 25 & 35 & \\
\hline$>10$ & 13 & 18 & 14 & 19 & \\
\hline
\end{tabular}


Table 2 Treatment characteristics
* 5 patients randomized in arm A were administered RT after chemo completion

\begin{tabular}{llll}
\hline & & Group A $(N=70)$ & Group B $(N=71)$ \\
\hline Number of cycles & Total & 387 & 351 \\
& Median (range) & $6(1-6)$ & $6(1-6)$ \\
Number of cycles per patient $N(\%)$ & 1 & $4(6)$ & $3(4)$ \\
& 2 & $1(1)$ & $4(6)$ \\
& 3 & $2(3)$ & $9(13)$ \\
& 4 & $1(1)$ & $2(3)$ \\
& 5 & $1(1)$ & $4(6)$ \\
Docetaxel DI (mg/m ${ }^{2} /$ week) & 6 & $61(82)$ & $49(69)$ \\
Docetaxel RDI & Median (range) & $24.6(14.3-25.7)$ & $16.0(6.0-34.4)$ \\
Cisplatin DI (mg/m ${ }^{2} /$ week) & Median (range) & $0.98(0.57-1.03)$ & $0.64(0.24-1.38)$ \\
Cisplatin RDI & Median (range) & $22.7(14.3-25.4)$ & $16.2(7.5-25.6)$ \\
Cumulative carboplatin & Median (range) & $0.91(0.57-1.02)$ & $0.64(0.30-1.02)$ \\
Dose (mg) & Median (range) & $2,885(420-4,430)$ & $2,400(300-4,420)$ \\
Patients treated with RT* & & & $60(85)$ \\
Duration (weeks) & $N(\%)$ & & $5.1(0.4-6.6)$ \\
Dose (rads) & Median (range) & & $4,500(3,000-6,040)$ \\
\hline
\end{tabular}

In order to identify the factors that had a significant effect on patients' OS and DFS, multivariate Cox regression analysis was performed. Variables included were age, number of involved nodes ( $0-7$ vs. $8-15 \mathrm{vs}>15)$, $\mathrm{T}$ stage $\left(\mathrm{T}_{1} / \mathrm{T}_{2}\right.$ vs. $\mathrm{T}_{3} / \mathrm{T}_{4}$ ), grade, histological subtype (intestinal vs. diffuse vs. mixed/unclassified), and randomization group. Statistical tests were two-sided and were performed to a significance level of 0.05 . Results of this study were presented according to reporting recommendations for tumor marker prognostic studies [26].

\section{Results}

\section{Patient characteristics}

A total of 147 patients were registered in the study between April 2002 and April 2005. Four patients were considered ineligible and were therefore not included in the analysis: 1 patient had liver metastases at the time of surgery, 2 patients had second primaries (esophageal and head and neck) and 1 patient had pT2N0 disease. The study flow is shown in Fig. 1. Selected baseline characteristics of the 143 eligible patients are summarized in Table 1. Seventy-one patients were randomized to receive adjuvant chemotherapy (arm A) and 72 were randomized to receive chemotherapy with RT ( $\operatorname{arm} \mathrm{B})$. There were no significant differences in major characteristics between the two treatment groups, with the exception of histological subtype $(P=0.007)$.
Treatment characteristics and toxicity

Treatment details and toxicity are shown in Table 2. Only treated patients with complete medical records were included in this analysis apart from the following cases: one patient $(\operatorname{arm} \mathrm{A})$ who did not receive protocol treatment and another patient (arm B) whose medical records were not available at the time of the analysis. Nine patients in group A (13\%) did not complete 6 cycles of treatment: 1 patient discontinued due to toxicity, 4 discontinued following disease progression, 3 withdrew consent, while for one patient the reason for noncompletion was unknown. In group B, 22 patients $(31 \%)$ did not complete six cycles of chemotherapy: 2 patients died, 5 discontinued due to toxicity, 3 experienced disease progression, 6 withdrew consent, 4 patients discontinued for other reasons, and 2 discontinued for unknown reasons. Discontinuation rate was significantly higher for patients treated in arm B (13\% vs. $31 \%, P=0.014)$. Sixty patients $(85 \%)$ from arm $\mathrm{B}$ received RT. Details of this treatment modality are shown in Table 3. DI and RDI for docetaxel and cisplatin were lower in arm B, as expected from the interruption of chemotherapy for the administration of RT.

Grade 3 or 4 toxicities observed in the two arms are shown in Table 3 . The most common grade $3 / 4$ toxicities for arms A and B (excluding alopecia) were non-febrile neutropenia (11\% vs. $17 \%$, respectively), febrile neutropenia ( $9 \%$ vs. $7 \%$ ), and diarrhea (7\% vs. $4 \%$, respectively). These differences were not significant. In addition, no significant differences between group A and B were found in the requirements for: hospitalization (13 [19\%] vs. 10 
Table 3 Incidence (\%) of grade 3-4 toxicities of the total population and according to the platinum compound used

\begin{tabular}{|c|c|c|c|c|}
\hline & \multicolumn{2}{|c|}{ Group A $(N=70)$} & \multicolumn{2}{|c|}{ Group B $(N=71)$} \\
\hline & Grade 3 & Grade 4 & Grade 3 & Grade 4 \\
\hline Anemia & $1(1)$ & & $1(1)$ & \\
\hline Neutropenia (non-febrile) & $6(9)$ & $2(3)$ & $4(7)$ & $8(11)$ \\
\hline Febrile Neutropenia & & $6(9)$ & & $5(7)$ \\
\hline Thrombocytopenia & $1(1)$ & & $3(4)$ & \\
\hline Nausea/Vomiting & $1(1)$ & & $3(4)$ & \\
\hline Stomatitis & & & $1(1)$ & \\
\hline Diarrhea & $4(6)$ & $1(2)$ & $3(4)$ & \\
\hline Infection & & & & $1(1)$ \\
\hline Peripheral Neuropathy & $1(1)$ & & & \\
\hline Fatigue & $1(1)$ & & & \\
\hline Allergic reaction & & $1(1)$ & & \\
\hline \multirow[t]{2}{*}{ Cisplatin treated } & \multicolumn{2}{|c|}{ Group A $(N=22)$} & \multicolumn{2}{|c|}{ Group B $(N=23)^{*}$} \\
\hline & Grade 3 & Grade 4 & Grade 3 & Grade 4 \\
\hline Neutropenia (non-febrile) & $2(9)$ & & $2(9)$ & $1(4)$ \\
\hline Febrile neutropenia & & $4(18)$ & & \\
\hline Thrombocytopenia & $1(4)$ & & & \\
\hline Nausea/Vomiting & $1(4)$ & & $2(9)$ & \\
\hline Diarrhea & $1(4)$ & & & \\
\hline Peripheral neuropathy & $1(4)$ & & & \\
\hline Allergic reaction & & $1(4)$ & & \\
\hline \multirow[t]{2}{*}{ Carboplatin treated } & \multicolumn{2}{|c|}{ Group A $(N=48)$} & \multicolumn{2}{|c|}{ Group B $(N=51)$} \\
\hline & Grade 3 & Grade 4 & Grade 3 & Grade 4 \\
\hline Anemia & $1(2)$ & & $1(2)$ & \\
\hline Neutropenia (non-febrile) & $4(8)$ & $2(4)$ & $4(8)$ & $7(14)$ \\
\hline Febrile neutropenia & & $2(4)$ & & $5(10)$ \\
\hline Thrombocytopenia & & & $3(6)$ & \\
\hline Nausea/Vomiting & & & $2(4)$ & \\
\hline Stomatitis & & & $1(2)$ & \\
\hline Diarrhea & $3(6)$ & $1(2)$ & $3(6)$ & \\
\hline Infection & & & & $1(2)$ \\
\hline Fatigue & $1(2)$ & & & \\
\hline
\end{tabular}

* 3 patients randomized in Arm B were treated with both Cisplatin and Carboplatin

[14\%]), red blood cell transfusion (2 [3\%] vs. 2 [3\%]), platelet transfusion $(2[3 \%]$ vs. $1[1 \%])$, requirement for G-CSF (32 [46\%] vs. 39 [59\%]), or antibiotic treatment (8 [11\%] vs. $12[17 \%])$.

\section{Efficacy results}

After a median follow-up of 53.7 months (range 0.1-77.8), 34 deaths and 37 relapses were observed in group A, while 40 deaths and 43 relapses were observed in group B. No
Table 4 Efficacy results and Multivariate Cox regression analysis

\begin{tabular}{|c|c|c|c|c|c|c|}
\hline & \multicolumn{3}{|c|}{ Survival (months) } & \multicolumn{3}{|c|}{ PFS (months) } \\
\hline \multirow[t]{4}{*}{ Group A } & \multicolumn{2}{|c|}{ Median } & $95 \% \mathrm{CI}$ & \multicolumn{2}{|c|}{ Median } & $95 \% \mathrm{CI}$ \\
\hline & & $38.1-72.5$ & & $13.6-60.3$ \\
\hline & \multicolumn{3}{|c|}{3 years } & \multicolumn{2}{|c|}{3 years } & \\
\hline & \multicolumn{2}{|c|}{$61 \%$} & & \multicolumn{2}{|c|}{$51 \%$} & \\
\hline \multirow[t]{6}{*}{ Group B } & \multicolumn{2}{|c|}{ Median } & $95 \% \mathrm{CI}$ & \multicolumn{2}{|c|}{ Median } & $95 \%$ CI \\
\hline & \multicolumn{2}{|c|}{44.5} & $28.6-60.5$ & \multicolumn{2}{|c|}{33.1} & $18.4-47.8$ \\
\hline & \multicolumn{3}{|c|}{3 years } & \multicolumn{2}{|c|}{3 years } & \\
\hline & \multicolumn{3}{|c|}{$57 \%$} & \multicolumn{2}{|c|}{$48 \%$} & \\
\hline & \multicolumn{6}{|c|}{ Multivariate analysis } \\
\hline & HR & $95 \%$ CI. & $P$ & HR & $95 \%$ CI. & $P$ \\
\hline \multicolumn{7}{|c|}{ Randomization group } \\
\hline A & 1 & - & - & 1 & - & - \\
\hline B & 1.20 & $0.75-1.9$ & 0.448 & 1.04 & $0.66-1.63$ & 0.879 \\
\hline \multicolumn{7}{|l|}{$\mathrm{T}$} \\
\hline $\mathrm{T} 1$ or $\mathrm{T} 2$ & 1 & - & - & 1 & - & - \\
\hline $\mathrm{T} 3$ or $\mathrm{T} 4$ & 2.65 & $1.26-5.5$ & 0.011 & 2.16 & $1.10-4.25$ & 0.026 \\
\hline \multicolumn{7}{|c|}{ Lymph nodes involved } \\
\hline $0-7$ & 1 & - & - & 1 & - & - \\
\hline $8-15$ & 2.92 & $1.66-5.1$ & $<0.001$ & 2.35 & $1.35-4.08$ & 0.002 \\
\hline$>15$ & 3.60 & $1.88-6.8$ & $<0.001$ & 4.07 & $2.17-7.66$ & $<0.001$ \\
\hline Age & 1.03 & $1.01-1.0$ & 0.018 & 1.03 & $1.00-1.05$ & 0.048 \\
\hline
\end{tabular}

difference in local recurrence rates was observed between the two arms ( $10 \%$ vs. $5 \%, P=0.246)$. Median and 3 -year OS and DFS for the two groups are shown in Table 4. No significant differences between the two groups were found (Fig. 2).

In the multivariate analysis (Table 4), $\mathrm{T}$ stage and lymph node involvement were found to be independent prognostic factors for OS and lymph node involvement for DFS. After adjusting for the significant factors, randomization group still did not have a significant effect on OS $(\mathrm{HR}=1.20$, 95\% CI: $0.75-1.91, P=0.448)$ or PFS (HR $=1.04,95 \% \mathrm{CI}$ : $0.66-1.63, P=0.879)$.

Study of molecular markers

Tissue blocks for molecular marker studies were obtained from 67 patients (group A: 35, group B: 32). Staining could not be assessed for all of the examined markers in two cases. The results of immunostaining in the 67 patients with at least one evaluated marker are shown in Table 5, while ERCC1, HER2, and MAP-Tau staining patterns are shown in Fig. 3. There was no association of any marker with pT, $\mathrm{N}$, differentiation, or TNM stage. In Table 6, distribution of protein expression according to histological subtype and tumor localization is presented. For gastric tumors, 5 out of 
Fig. 2 Kaplan-Meier curves for the OS (a) and DFS (b) of patients randomized to arm $\mathrm{A}$ (blue line) or arm B (red line)
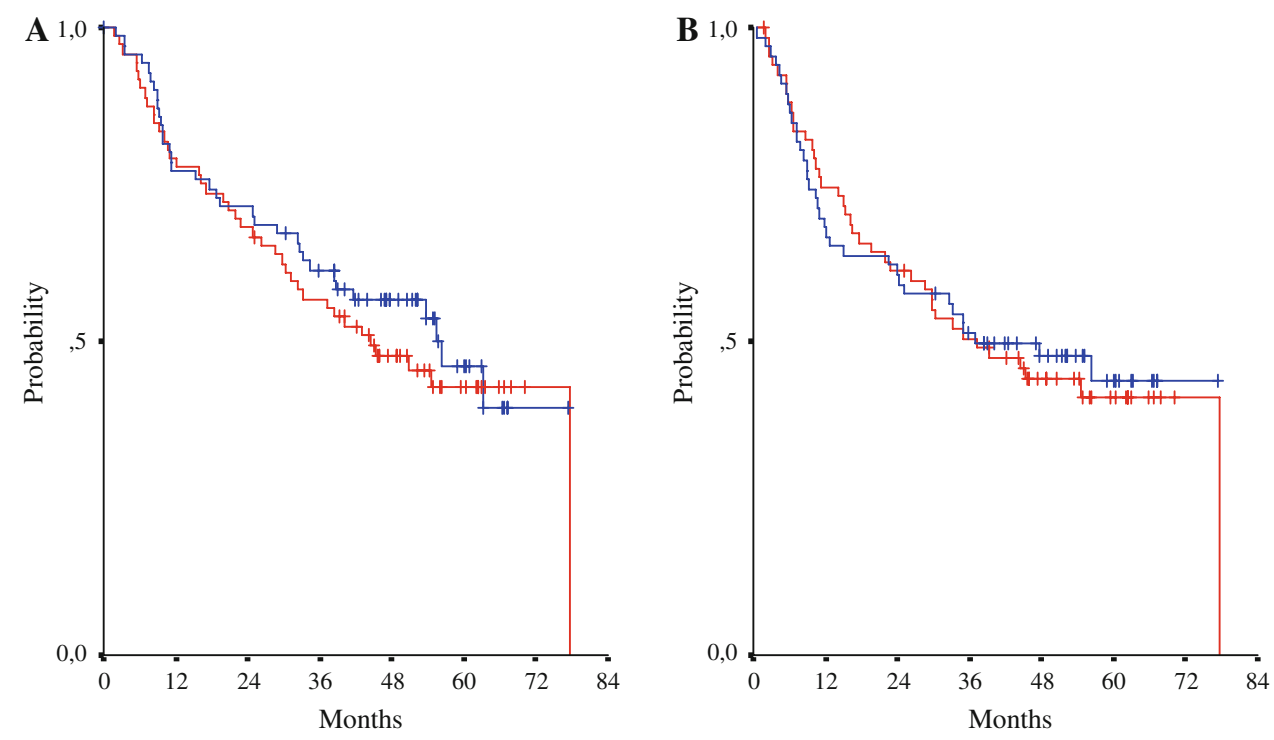

Table 5 Immunohistochemical results in 67 tumor tissue samples available for protein analysis

\begin{tabular}{lllll}
\hline Protein & $\begin{array}{l}\text { Expression } \\
\text { Status } N(\%)\end{array}$ & $\begin{array}{l}\text { Arm A } \\
(N=34)\end{array}$ & $\begin{array}{l}\text { Arm B } \\
(N=32)\end{array}$ & $\begin{array}{l}\text { Total } \\
(N=66)\end{array}$ \\
\hline EGFR & Negative & $22(65)$ & $22(69)$ & $44(67)$ \\
& Positive & $12(35)$ & $10(31)$ & $22(33)$ \\
HER2 & Negative & $32(94)$ & $29(91)$ & $61(92)$ \\
& Positive & $2(6)$ & $3(9)$ & $5(8)$ \\
ERCC1 & Negative & $10(29)$ & $10(32)$ & $20(30)$ \\
& Positive & $25(71)$ & $21(68)$ & $46(70)$ \\
MAP-Tau & Negative & $18(53)$ & $18(56)$ & $36(55)$ \\
& Positive & $16(47)$ & $14(44)$ & $30(45)$ \\
MET/HGFR & Negative & $6(18)$ & $7(22)$ & $13(20)$ \\
& Positive & $28(82)$ & $25(78)$ & $53(80)$ \\
PTEN & Negative & $25(74)$ & $26(81)$ & $51(77)$ \\
& Positive & $9(26)$ & $6(19)$ & $15(23)$ \\
\hline
\end{tabular}

* For each marker staining could not be assessed in one sample

50 cases were HER 2 positive ( 3 intestinal and 2 diffuse), while in gastroesophageal junction (GEJ) tumors HER2 positivity was not observed. The only marker significantly associated with OS and DFS was ERCC1: median OS for negative tumors was 18.8 months (95\% CI 12.2-25.5), while the respective median for positive tumors was 63.2 months (95\% CI 29.7-96.7; log-rank, $P=0.046$, $\mathrm{HR}=0.51$, [95\% CI: 0.26-1.00]; Figure 4a). After adjustment for randomization arm, the difference remained marginally significant (Wald, $P=0.046$ ).

Similarly, median DFS for ERCC1 negative tumors was 11.8 months (95\% CI 8.7-15), while the respective median for positive tumors was 33.1 months (95\% CI 3.6-62.7; log-rank, $P=0.018, \mathrm{HR}=0.47$, [95\% CI: $0.25-0.89]$; Figure $4 \mathrm{~b})$. After adjustment for randomization arm, the difference remained significant (Wald, $P=0.016$ ).

\section{Discussion}

We assessed the benefit from the combination of RT with docetaxel and carboplatin/cisplatin chemotherapy compared to chemotherapy alone in patients with radically resected gastric cancer at high-risk for relapse. At a median follow-up of approximately 54 months, there were no differences between the two therapies in OS and DFS. Our entry criteria resulted in a cohort of high-risk patients, with most of them having stage III or IV disease. Contemporary surgical series form Europe and the USA estimate longterm DFS in similar populations below $40 \%$ [8, 9]. For this reason, we believe that our findings are relevant to the recent developments in adjuvant therapy in gastric cancer.

Recent randomized studies [8-10] established adjuvant therapy as a standard approach, since all of them showed a survival benefit over no adjuvant therapy. However, the optimal type of adjuvant therapy remains to be determined. Our findings indicate that RT may not add any benefit to modern, efficient chemotherapy combinations. This is of clinical relevance, considering the toxicity as well as problems of quality assurance associated with RT, particularly when used as adjuvant therapy in gastric cancer. Indeed, the administration of RT by many centers made monitoring of the quality of RT very difficult. Every effort should be made, however, for central quality-assurance review of the radiotherapy plan in clinical trials, similar to that adopted by the MacDonald study [8]. Another explanation of the lack of a benefit by the addition of RT may be the lower DI of chemotherapy in arm B because of the administration of RT between cycles 3 and 4 . Thus, our results may reflect a lack of benefit due to the interruption of the administration of the chemotherapy combination.

Other limitations of this study should also be considered in the interpretation of our results. This study was powered 
Fig. 3 Immunohistochemistry performed on tissue microarrays. a ERCC1 strong nuclear positivity; b ERCC1 staining in a small number of neoplastic cells similar to the staining intensity of stromal fibroblasts (regarded as negative staining); c HER2 strong membraneous staining; d MAP-Tau intense cytoplasmic staining; original magnification $\times 100$; insets $\times 200$
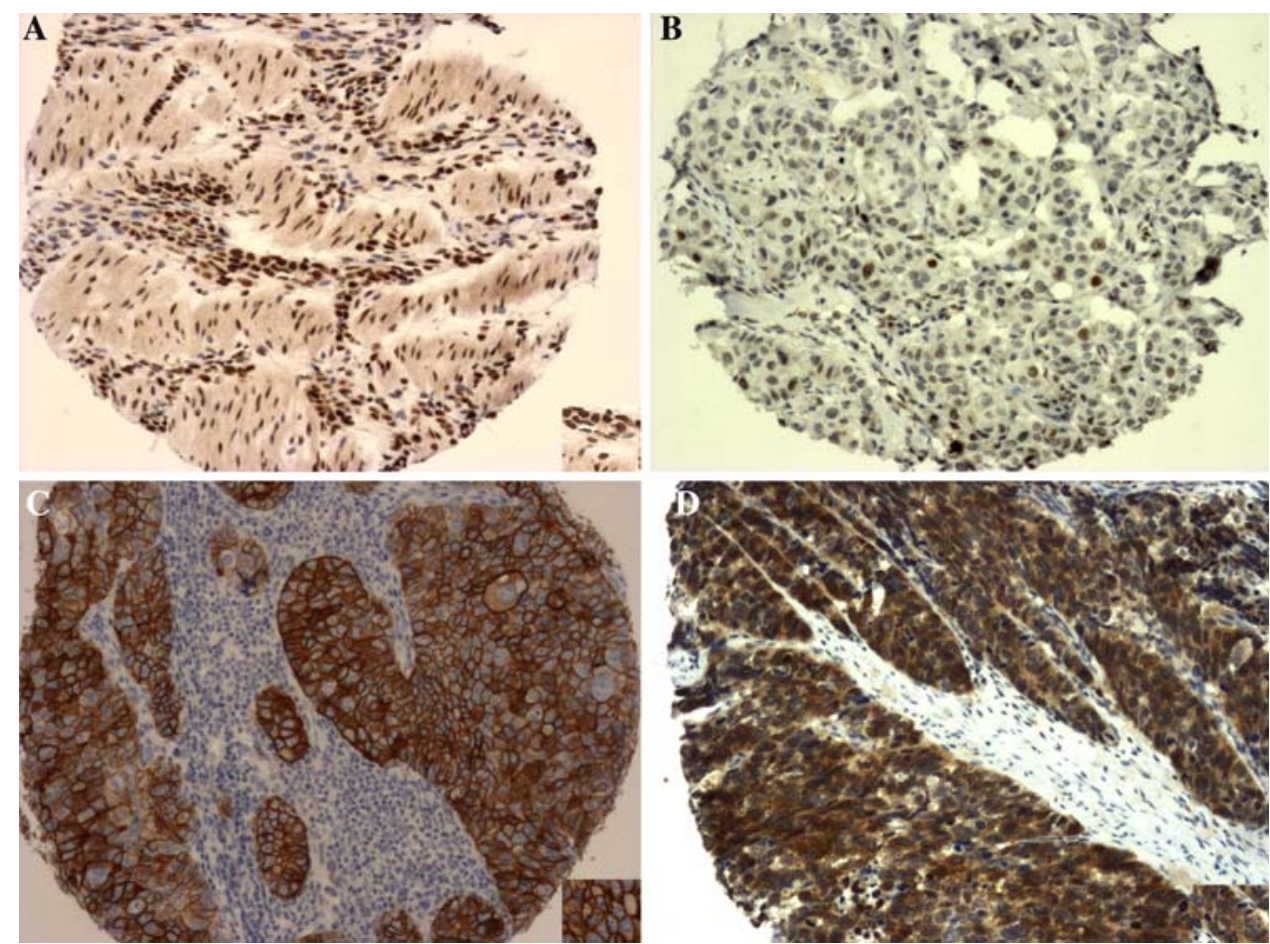

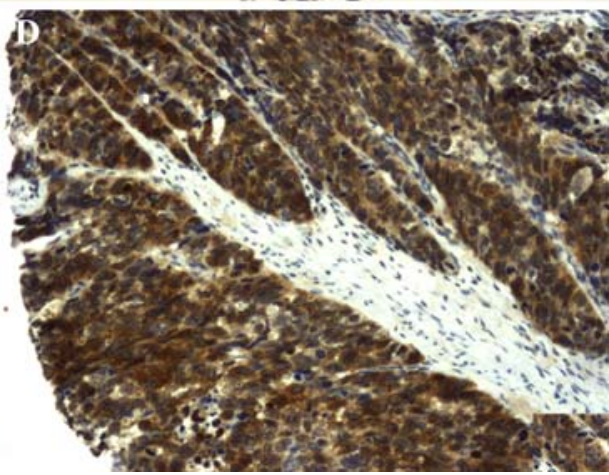

to demonstrate a $20 \%$ survival benefit of adjuvant chemoradiotherapy over adjuvant chemotherapy alone. Since only 147 instead of the required 200 patients were randomized, it was underpowered to test the initial hypothesis. Specifically, having observed 74 deaths $(68 \%$ of the total events needed according to study design) the post hoc power was $66 \%$. The possibility, therefore, that a benefit by the addition of RT was not detected due to decreased power of the study should not be excluded.

Another assumption was that the chemotherapeutic combination would have had proven efficacy in advanced disease. Although this is true for the combination of docetaxel/cisplatin, most patients received docetaxel/carboplatin, which is a less established regimen in advanced gastric cancer. The substitution was decided because nausea and vomiting were reported frequently for docetaxel/cisplatin. In the same context, regarding the choice of the chemotherapy regimen, other better-studied combinations, such as ECF, which has previously been used perioperatively [9], could have been used. In addition, despite having set criteria for the experience of surgeons, D1 and D2 resections were reported in only $34 \%$ of the eligible patients (50\% among those with known type of resection). Nevertheless, the last two limitations should have, if anything, strengthened the contribution of RT. This was not, however, reflected in the results.

Although treatment was generally well tolerated, a sizeable subset of the patients did not complete protocol treatment. This subset was significantly higher in the radiochemotherapy arm and consistent with the data reported by
McDonald et al. [8]. In 6 cases, therapy was discontinued during RT, reflecting the significant toxicity that this modality can be associated with.

In the absence of any significant differences in survival between the randomization arms, we sought to determine whether molecular markers might identify groups of patients more likely to benefit from the administration of adjuvant therapy. We have previously reported a study of molecular markers and their prognostic role in gastric cancer [27]. In this study, a panel of 5 biomarkers, Topo I, Topo II $\alpha$, VEGF, E-Cadherin, and thymidylate synthase (TS) had been evaluated in 46 patients treated postoperatively with irinotecan and docetaxel, with none of the biomarkers shown to be of prognostic value, probably due to the small number of patients.

In the current study, a different panel of biomarkers was selected with a similar approach and rational. Hence, among a variety of potentially relevant molecules, ERCC1 and MAP-Tau were selected because they are involved in the process of 'recovery' from the platinum and taxane cytotoxic effect, respectively [28-30]. Moreover, the expression of tyrosine kinase receptors (TKRs), such as HER2, EGFR and MET, has being thoroughly investigated [31-33] in solid tumors, but findings in gastric cancer are still controversial. Also, the role of the PTEN protein in gastric cancer is still unknown, whereas loss of heterozygosity of the relevant gene is found in many solid tumors.

The results of ERCC1 overexpression in our study appear to be inconsistent with the so far published data. Patients with positive ERCC1 (46 of 67, and 69\%) had 
Table 6 Association of histological type and protein expression according to tumor localization

\begin{tabular}{|c|c|c|c|c|}
\hline \multirow[t]{2}{*}{$\begin{array}{l}\text { Tumor } \\
\text { localization }\end{array}$} & \multirow[t]{2}{*}{$\begin{array}{l}\text { Expression } \\
\text { status }\end{array}$} & $\begin{array}{l}\text { Intestinal } \\
(n=9)\end{array}$ & $\begin{array}{l}\text { Diffuse } \\
(n=6)\end{array}$ & $\begin{array}{l}\text { Mixed/ } \\
\text { Unclassified } \\
(n=1)\end{array}$ \\
\hline & & $N(\%)$ & $N(\%)$ & $N(\%)$ \\
\hline \multicolumn{5}{|l|}{ GEJ } \\
\hline \multirow[t]{2}{*}{ EGFR } & Negative & $6(67)$ & $2(33)$ & $1(100)$ \\
\hline & Positive & $3(33)$ & $4(67)$ & $0(0)$ \\
\hline \multirow[t]{2}{*}{ ERCC1 } & Negative & $3(33)$ & $1(17)$ & $0(0)$ \\
\hline & Positive & $6(67)$ & $5(83)$ & $1(100)$ \\
\hline \multirow[t]{2}{*}{ HER 2} & Negative & $9(100)$ & $6(100)$ & $1(100)$ \\
\hline & Positive & $0(0)$ & $0(0)$ & $0(0)$ \\
\hline \multirow[t]{2}{*}{ MAP-Tau } & Negative & $4(44)$ & $3(50)$ & $0(0)$ \\
\hline & Positive & $5(56)$ & $3(50)$ & $1(100)$ \\
\hline \multirow[t]{2}{*}{ MET/HGFR* } & Negative & $0(0)$ & $4(67)$ & $1(100)$ \\
\hline & Positive & $9(100)$ & $2(33)$ & $0(0)$ \\
\hline \multirow[t]{2}{*}{ PTEN } & Negative & $1(11)$ & $3(50)$ & $0(0)$ \\
\hline & Positive & $8(89)$ & $3(50)$ & $1(100)$ \\
\hline \multirow[t]{2}{*}{$\begin{array}{l}\text { Tumor } \\
\text { localization }\end{array}$} & $\begin{array}{l}\text { Expression } \\
\text { status }\end{array}$ & $\begin{array}{l}\text { Intestinal } \\
(n=21)\end{array}$ & $\begin{array}{l}\text { Diffuse } \\
(n=25)\end{array}$ & $\begin{array}{l}\text { Mixed/ } \\
\text { Unclassified } \\
(n=4)\end{array}$ \\
\hline & & $N(\%)$ & $N(\%)$ & $N(\%)$ \\
\hline \multicolumn{5}{|l|}{ Gastric } \\
\hline \multirow[t]{2}{*}{ EGFR } & Negative & $16(76)$ & $17(68)$ & $2(50)$ \\
\hline & Positive & $5(24)$ & $8(32)$ & $2(50)$ \\
\hline \multirow[t]{2}{*}{ ERCC1 } & Negative & $8(38)$ & $7(28)$ & $1(25)$ \\
\hline & Positive & $13(62)$ & $18(72)$ & $3(75)$ \\
\hline \multirow[t]{2}{*}{ HER2 } & Negative & $18(86)$ & $23(92)$ & $4(100)$ \\
\hline & Positive & $3(14)$ & $2(8)$ & $0(0)$ \\
\hline \multirow[t]{2}{*}{ MAP-Tau } & Negative & $13(62)$ & $14(56)$ & $2(50)$ \\
\hline & Positive & $8(38)$ & $11(44)$ & $2(50)$ \\
\hline \multirow[t]{2}{*}{ MET/HGFR } & Negative & $2(10)$ & $5(20)$ & $1(25)$ \\
\hline & Positive & $19(90)$ & $20(80)$ & $3(75)$ \\
\hline \multirow[t]{2}{*}{ PTEN } & Negative & $4(19)$ & $7(28)$ & $0(0)$ \\
\hline & Positive & $17(81)$ & $18(72)$ & $4(100)$ \\
\hline
\end{tabular}

GEJ: gastroesophageal junction

* $P=0.048$

significantly longer OS and DFS compared to those who did not overexpress the protein. ERCC1 expression has previously been evaluated in metastatic gastric cancer by Kwon et al. [34]. In that study, 64 patients with advanced gastric cancer were evaluated for ERCC1, among other markers. Seventy percent $(70 \%)$ of the patients were ERCC1 positive and had a poor response to treatment. Two more studies confirmed their findings $[35,36]$, but no published data in operable gastric cancer treated with docetaxel/cisplatin or carboplatin exist so far. In non-small cell lung (NSCLC) cancer, however, the role of ERCC1 [37, 38] as a key protein in nucleotide repair of platinum- induced DNA intrastrand breaks has been confirmed. Olaussen et al. [39] evaluated ERCC1 by immunohistochemistry (IHC) in 761 patients with operable NSCLC. ERCC1 negative patients had significantly longer survival when treated with platinum-based chemotherapy. Nevertheless, expression of ERCC1 was associated with improved outcome in the whole population, indicating a prognostic role, independently of its predictive value. It is plausible that the prognostic role of ERCC1 expression prevailed in our study over its predictive value. Unfortunately, all of our patients received platinum-based chemotherapy and, therefore, we could not test this hypothesis in a cohort of non-treated patients. Nevertheless, our results appear to be contradictory and await validation in future studies with larger number of patients.

As for the Tau protein, it belongs to the microtubuleassociated proteins (MAP). The MAP group controls the assembly of $\alpha$ and $\beta$ tubulin dimmers to form microtubules [40]. When bound to microtubules, MAP-Tau promotes their polymerization and stabilization [41]. Taxanes, on the other hand, although they have a similar way of interacting with tubulin [42], alter the tubulin dynamics in a way that eventually leads to cell cycle arrest and apoptosis [43]. Wagner P et al. [44], published an analysis of patients with breast cancer who had pathologic complete response after neo-adjuvant chemotherapy with taxanes. Decreased MAPTau expression was associated with sensitivity to taxanes. These results have been validated in other studies, both in breast cancer [45] and NSCLC patients [46]. In gastric cancer, Mimori et al. [23] have published results from a study of MAP-Tau protein expression in 20 patients with metastatic gastric cancer. All MAP-Tau negative patients $(6 / 20)$ responded to taxanes. Although there is little doubt of the emerging role of MAP-Tau as a predictive marker for taxane-based chemotherapy, no correlation with survival has, so far, been validated. In our study, 36 patients (54\%) were MAP-Tau negative. There were no statistically significant differences in OS or DFS, related with the protein expression. The predictive value of MAP-Tau could not be evaluated in our population, since both arms received docetaxel. Moreover, the small number of patients renders these results controversial.

Regarding HER2 protein expression, evaluation with IHC in gastric cancer is equally accurate as in breast cancer [47]. HER2 is overexpressed in 6-22\% of patients with gastric cancer [48, 49] and appears to result in favorable prognosis [48], however, later publications did not confirm this finding. On the contrary, poor prognosis, higher probability of lymph node involvement and increased number of postoperative relapses was reported in other studies [50, 51]. In our study, 61 of 67 patients $(91 \%)$ were HER2 negative, while 5 patients $(7 \%)$ were positive. There was no correlation with OS or DFS. 
Fig. 4 Kaplan-Meier curve of OS (a) and DFS (b) according to ERCC1 expression in 66 patients treated with adjuvant therapy. The red line corresponds to patients with positive ERCC1 expression and the blue line to patients with negative ERCC1 expression

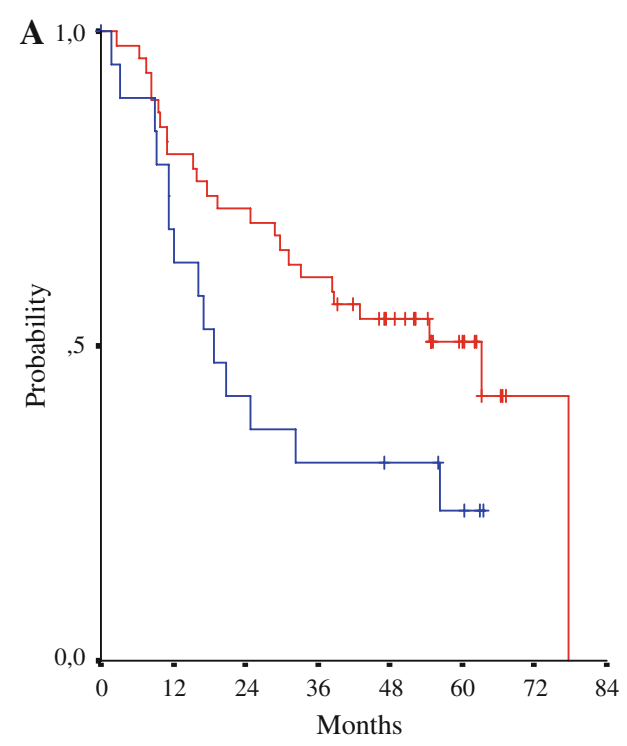

The percentage of HER 2 positive patients observed in our study (7\%) is much lower than the $22 \%$ reported in the ToGA trial [49], which included 3,800 patients centrally tested for HER2. The discrepancy might possibly be due to differences in the IHC evaluation criteria used (staining of $30 \%$ of cells was required in our study as opposed to $10 \%$ in the ToGA trial). Another possible explanation for the discordance might have been the observed high percentage of heterogeneous tumors in gastric cancer combined with the small number of tumors evaluated in our study.

In conclusion, our results indicate that the role of RT as an adjuvant treatment of gastric cancer may change with the evolution of modern chemotherapeutic combinations, which may prove to be more effective than those previously used. The optimal adjuvant strategy and the incorporation of various modalities in such approaches should therefore be further investigated. Finally, more thorough evaluation of molecular markers may lead to the identification of subsets of patients more likely to benefit from different strategies of adjuvant treatment.

Acknowledgments The authors wish to thank Ms. Evita Fragou for monitoring the study, Ms. Maria Moschoni for coordinating the data management, Ms. Thalia Spinari for coordinating tumor tissue collection (all at the HeCOG Data Office, Athens), and Sophia Chrisafi Ph.D. for excellent technical assistance. Supported in part by a $\mathrm{HeCOG}$ Research Grant: RD/2

Conflict of interest statement No author declared any conflict of interest.

\section{References}

1. Van Cutsem E, Dicato M, Arber N, Benson A, Cunningham D, Diaz-Rubio E, Glimelius B, Goldberg R, Haller D, Haustermans K, Koo-Kang Y, Labianca R, Lang I, Minsky B, Nordlinger B,
Roth A, Rougier P, Schmoll HJ, Sobrero A, Tabernero J, Szawlowski A, van de Velde C (2006) The neo-adjuvant, surgical and adjuvant treatment of gastric adenocarcinoma. Current expert opinion derived from the Seventh World Congress on Gastrointestinal Cancer, Barcelona, 2005. Ann Oncol 17(Suppl 6):vi13-vi18. doi:10.1093/annonc/mdl976

2. FerlayJ, Bray F, Pisani P, Parkin DM (2001) Cancer incidence, mortality and prevalence worldwide, version 1.0. Lyon IARC Press, IARC Cancer Base No. 5

3. Catalano V, Labianca R, Beretta GD, Gatta G, de Braud F, Van Cutsem E (2005) Gastric cancer. Crit Rev Oncol Hematol 54:209241. doi:10.1016/j.critrevonc.2005.01.002

4. Ajani JA (2005) Evolving chemotherapy for advanced gastric cancer. Oncologist 10(Suppl 3):49-58

5. Macdonald JS (2004) Clinical overview: adjuvant therapy of gastrointestinal cancer. Cancer Chemother Pharmacol 54(Suppl 1):S4-S11. doi:10.1007/s00280-004-0880-4

6. Sastre J, Garcia-Saenz JA, Diaz-Rubio E (2006) Chemotherapy for gastric cancer. World J Gastroenterol 12:204-213

7. Cunningham D, Jost LM, Purkalne G, Oliveira J (2005) ESMO Guidelines Task Force. ESMO Minimum Clinical Recommendations for diagnosis, treatment and follow-up of gastric cancer. Ann Oncol 16(Suppl 1):i22-i23. doi:10.1093/annonc/mdi812

8. Macdonald JS, Smalley SR, Benedetti J, Hundahl SA, Estes NC, Stemmermann GN, Haller DG, Ajani JA, Gunderson LL, Jessup JM, Martenson JA (2001) Chemoradiotherapy after surgery compared with surgery alone for adenocarcinoma of the stomach or gastroesophageal junction. N Engl J Med 345:725-730

9. Cunningham D, Allum WH, Stenning SP, Thompson JN, Van de Velde CJ, Nicolson M, Scarffe JH, Lofts FJ, Falk SJ, Iveson TJ, Smith DB, Langley RE, Verma M, Weeden S, Chua YJ MAGIC, Participants Trial (2006) Perioperative chemotherapy versus surgery alone for resectable gastroesophageal cancer. N Engl J Med 355:11-20

10. Sakuramoto S, Sasako M, Yamaguchi T, Kinoshita T, Fujii M, Nashimoto A, Furukawa H, Nakajima T, Ohashi Y, Imamura H, Higashino M, Yamamura Y, Kurita A, Arai K, Group ACTS-GC (2007) Adjuvant chemotherapy for gastric cancer with S-1, an oral fluoropyrimidine. N Engl J Med 357:1810-1820

11. Sulkes A, Smyth J, Sessa C, Dirix LY, Vermorken JB, Kaye S, Wanders J, Franklin H, LeBail N, Verweij J (1994) Docetaxel (Taxotere) in advanced gastric cancer: results of a phase II clinical trial. EORTC Early Clinical Trials Group. Br J Cancer 70:380-383 
12. Thuss-Patience PC, Kretzschmar A, Repp M, Kingreen D, Hennesser D, Micheel S, Pink D, Scholz C, Dorken B, Reichardt $P$ (2005) Docetaxel and continuous-infusion fluorouracil versus epirubicin, cisplatin, and fluorouracil for advanced gastric adenocarcinoma: a randomized phase II study. J Clin Oncol 23:494-501. doi:10.1200/JCO.2005.02.163

13. Roth AD, Maibach R, Martinelli G, Fazio N, Aapro MS, Pagani O, Morant R, Borner MM, Herrmann R, Honegger H, Cavalli F, Alberto P, Castiglione M, Goldhirsch A, Swiss Group for Clinical Cancer Research (SAKK), The European Institute of Oncology (EIO) (2000) Docetaxel (Taxotere)-cisplatin (TC): an effective drug combination in gastric carcinoma. Ann Oncol 11:301-306

14. Ridwelski K, Gebauer T, Fahlke J, Kroning H, Kettner E, Meyer F, Eichelmann K, Lippert H (2001) Combination chemotherapy with docetaxel and cisplatin for locally advanced and metastatic gastric cancer. Ann Oncol 12:47-51

15. Smith I, Procter M, Gelber RD et al (2007) 2-year follow up of trastuzumab after adjuvant chemotherapy in HER2-positive breast cancer: a randomised controlled trial. Lancet 369:29-36

16. Dowsett M, Dunbier AK (2004) Emerging biomarkers and new understanding of traditional markers in personalized therapy for breast cancer. Clin Cancer Res 14(24):8019-8026

17. de Castro-Carpeño J, Belda-Iniesta C, Casado Sáenz E, Hernández Agudo E, Feliu Batlle J, González Barón M (2008) EGFR and colon cancer: a clinical view. Clin Transl Oncol 10(1):6-13

18. Scartozzi M, Galizia E, Freddari F et al (2004) Molecular biology of sporadic gastric cancer: prognostic indicators and novel therapeutic approaches. Cancer Treat Rev 30:451-459

19. Greene F, Page D, Fleming ID, et al. (2002) Stomach. In: AJCC cancer staging manual. New York: Springer-Verlaag, pp 99

20. Williams JH, Mepham BL, Wright DH (1997) Tissue preparation for immunocytochemistry. J Clin Pathol 50:422-428

21. Nakajima M, Sawada H, Yamada Y, Watanabe A, Tatsumi M, Yamashita J, Matsuda M, Sakaguchi T, Hirao T, Nakano H (1999) The prognostic significance of amplification and overexpression of c-met and c-erb B-2 in human gastric carcinomas. Cancer 85(9):1894-1902

22. Kwon HC, Roh MS, Oh SY, Kim SH, Kim MC, Kim JS, Kim HJ (2007) Prognostic value of expression of ERCC1, thymidylate synthase, and glutathione S-transferase P1 for 5-fluorouracil/oxaliplatin chemotherapy in advanced gastric cancer. Ann Oncol 18(3):504-509

23. Mimori K, Sadanaga N, Yoshikawa Y, Ishikawa K, Hashimoto M, Tanaka F, Sasaki A, Inoue H, Sugimachi K, Mori M (2006) Reduced tau expression in gastric cancer can identify candidates for successful Paclitaxel treatment. Br J Cancer 94(12):1894-1897

24. Scartozzi M, Bearzi I, Berardi R, Mandolesi A, Fabris G, Cascinu S (2005) Epidermal growth factor receptor (EGFR) status in primary colorectal tumors does not correlate with EGFR expression in related metastatic sites: implications for treatment with EGFR-targeted monoclonal antibodies. J Clin Oncol 22:4772-4778

25. Perren A, Weng LP, Boag AH, Ziebold U, Thakore K, Dahia PL et al (1999) Immunohistochemical evidence of loss of PTEN expression in primary ductal adenocarcinomas of the breast. Am J Pathol 155(4):1253-1260

26. McShane LM, Altman DG, Sauerbrei W et al (2005) Reporting recommendations for tumor marker prognostic studies. J Clin Oncol 23:9067-9072

27. Skarlos DV, Bai M, Goussia A, Samantas E, Galani E, Tsavdaridis D, Karina M, Papakostas P, Konstantara A, Fountzilas G (2007) Expression of a molecular marker panel as a prognostic tool in gastric cancer patients treated postoperatively with docetaxel and irinotecan. A study of the Hellenic Cooperative Oncology Group. Anticancer Res 27(4C):2973-2983
28. Tanaka S, Nohara T, Iwamoto M et al (2009) Tau expression and efficacy of paclitaxel treatment in metastatic breast cancer. Cancer Chemother Pharmacol 64:341-346

29. Huang ZH, Hua D, Du X et al (2008) ERCC1 polymorphism, expression and clinical outcome of oxaliplatin-based adjuvant chemotherapy in gastric cancer. World J Gastrenterol 14:6401-6407

30. Bellmunt J, Paz-Ares L, Cuello M et al (2007) Gene expression of ERCC1 as a novel prognostic marker in advanced bladder cancer patients receiving cisplatin-based chemotherapy. Ann Oncol 18:522-528

31. Kopp R, Ruge M, Rothbauer E et al (2002) Impact of epidermal growth factor (EGF) radioreceptor analysis on long-term survival of gastric cancer patients. Anticancer Res 22:1161-1167

32. Garcia I, Vizoso F, Martin A et al (2003) Clinical significance of the epidermal growth factor receptor and HER2 receptor in resectable gastric cancer. Ann Surg Oncol 10:234-241

33. Lim EH, Zhang SL, Li ZL et al (2009) Using whole genome amplification (WGA) of low-volume biopsies to assess the prognostic role of EGFR, KRAS, p53, and cMET mutations in advanced-stage non-small cell lung cancer (NSCLC). J Thor Oncol 4:12-21

34. Kwon HC, Roh MS, Oh SY, Kim SH, Kim MC, Kim JS, Kim HJ (2007) Prognostic value of expression of ERCC1, thymidylate synthase, and glutathione S-transferase P1 for 5-fluorouracil/oxaliplatin chemotherapy in advanced gastric cancer. Ann Oncol 18(3):504-509

35. Wei J, Zou Z, Qian X, Ding Y, Xie L, Sanchez JJ, Zhao Y, Feng J, Ling Y, Liu Y, Yu L, Rosell R, Liu B (2008) ERCC1 mRNA levels and survival of advanced gastric cancer patients treated with a modified FOLFOX regimen. Br J Cancer 98(8):1398-1402 Epub 2008 Mar 25

36. Matsubara J, Nishina T, Yamada Y, Moriwaki T, Shimoda T, Kajiwara T, Nakajima TE, Kato K, Hamaguchi T, Shimada Y, Okayama Y, Oka T, Shirao K (2008) Impacts of excision repair cross-complementing gene 1 (ERCC1), dihydropyrimidine dehydrogenase, and epidermal growth factor receptor on the outcomes of patients with advanced gastric cancer. Br J Cancer 98(4):832839 Epub 2008 Jan 29

37. Siddik ZH (2003) Cisplatin: mode of cytotoxic action and molecular basis of resistance. Oncogene 22:7265-7279

38. Reed E (1998) Platinum-DNA adduct, nucleotide excision repair and platinum based anti-cancer chemotherapy. Cancer Treat Rev 24:331-344

39. Olaussen KA, Dunant A, Fouret P, Brambilla E, André F, Haddad V, Taranchon E, Filipits M, Pirker R, Popper HH, Stahel R, Sabatier L, Pignon JP, Tursz T, Le Chevalier T, Soria JC IALT, Investigators Bio (2006) DNA repair by ERCC1 in non-small-cell lung cancer and cisplatin-based adjuvant chemotherapy. N Engl J Med 355(10):983-991

40. Nogales E, Wolf SG, Downing KH (1998) Structure of the alpha beta tubulin dimer by electron crystallography. Nature 391(6663):199-203. Erratum in: Nature 1998 May 14;393 (6681): 191

41. Drechsel DN, Hyman AA, Cobb MH, Kirschner MW (1992) Modulation of the dynamic instability of tubulin assembly by the microtubule-associated protein tau. Mol Biol Cell 3:1141-1154

42. Nogales E, Wolf SG, Khan IA, Ludueña RF, Downing KH (1995) Structure of tubulin at $6.5 \mathrm{~A}$ and location of the taxol-binding site. Nature 375(6530):424-427

43. Yvon AC, Wadsworth P, Jordan MA (1999) Taxol suppresses dynamics of individual microtubules in living human tumor cells. Mol Biol Cell 10:947-959

44. Wagner P, Wang B, Clark E, Lee H, Rouzier R, Pusztai L (2005) Microtubule associated protein (MAP)-Tau: a novel mediator of paclitaxel sensitivity in vitro and in vivo. Cell Cycle 4(9):11491152 
45. Rouzier R, Rajan R, Wagner P, Hess KR, Gold DL, Stec J, Ayers M, Ross JS, Zhang P, Buchholz TA, Kuerer H, Green M, Arun B, Hortobagyi GN, Symmans WF, Pusztai L (2005) Microtubuleassociated protein tau: a marker of paclitaxel sensitivity in breast cancer. Proc Natl Acad Sci USA 102:8315-8320

46. Rosell R, Felip E (2001) Predicting response to paclitaxel/carboplatin-based therapy in non-small cell lung cancer. Semin Oncol 28(4 Suppl 14):37-44

47. Takehana $\mathrm{T}$, Kunitomo $\mathrm{K}$, Kono $\mathrm{K}$, Kitahara $\mathrm{F}$, Iizuka $\mathrm{H}$, Matsumoto Y, Fujino MA, Ooi A (2002) Status of c-erbB-2 in gastric adenocarcinoma: a comparative study of immunohistochemistry, fluorescence in situ hybridization and enzyme-linked immuno-sorbent assay. Int J Cancer 98(6):833-837

48. Jain S, Filipe MI, Gullick WJ, Linehan J, Moris RW (1991) c-erbB-2 protooncogene expression and its relationship to survival in gastric carcinoma: an immunohistochemical study on archive material. Int J Cancer 48:668-671

49. Van Cutsem E, Kang Y, Chung H, Shen L, Sawaki A, Lordick F, et al. (2009) Efficacy results from the ToGA trial: A phase III study of trastuzumab added to standard chemotherapy (CT) in first-line human epidermal growth factor receptor 2 (HER2)-positive advanced gastric cancer (GC). J Clin Oncol 27(18S): LBA4509

50. Yonemura Y, Ninomiya I, Yamaguchi A, Fushida S, Kimura H, Ohoyama S et al (1991) Evaluation of immunoreactivity for erbB2 protein as a marker of poor short term prognosis in gastric cancer. Cancer Res 51:1034-1038

51. Mizutani T, Onda M, Tokunaga A, Yamanaka N, Sugisaki Y (1993) Relationship of c-erbB-2 protein expression and gene amplification to invasion and metastasis in human gastric cancer. Cancer 72:2083-2088 